Session 2793

\title{
USING INTRANET TOOLS TO TEACH A PROJECT PROPOSAL PREPARATION COURSE IN ENGINEERING TECHNOLOGY
}

\author{
Albert Lozano-Nieto \\ Penn State University at Wilkes-Barre \\ P.O. Box PSU \\ Lehamn, PA 18627 \\ Phone: (570) 675-9245 \\ FAX: (570): 675-7713 \\ email: AXL17@psu.edu
}

\section{INTRODUCTION}

This paper describes the use of an Intranet Tool (First Class ${ }^{\mathrm{TM}}$ ) to carry out a Projects Proposal course. Although the experiences described here are specifically from a course in Electrical Engineering Technology, the author believes that the approach to the course, the use of the tools and the conclusions that we reach can be easily transportable to other design and project courses. First Class ${ }^{\mathrm{TM}}$ is an Intranet tool that allows users to post messages in "conferences" as well as real-time chat. All students enrolled in EET 419 (Project Proposal preparation) at the WilkesBarre campus of Penn State University receive a First Class ${ }^{\mathrm{TM}}$ account as well as training on how to use the system, carried out by the Instructional Design Specialist. The goal of the course EET 419 is for the students to develop a formal proposal for a project that will be built in their next semester. This course has been divided into a series of ten different outcomes or milestones, each one being a complete subtask that will be built into the final proposal.

The main idea and goal in the use of Intranet in this course is to create an environment where the students can talk and discuss ideas about their projects, engage in critical discussions of other projects, share information, etc. Because of the characteristics of the Campus (a commuter campus in a rural setting), it is not easy for the students to have a sense of belonging to a group as students in other locations do. It is also difficult for them to find a common time where they can meet to discuss their projects. By using First Class ${ }^{\mathrm{TM}}$, the students connect from their respective locations so they can work on their tasks in an asynchronous mode and have a successful interaction with their peers. Our main goal in structuring this course around First Class $^{\mathrm{TM}}$ is to create a virtual learning community that will provide the students with the best environment to nurture their intellectual curiosity. This paper will also focus on tools used to assess the effect of the use the Intranets in the course as well as the student's perceptions fn using technology for this kind of courses. 


\section{COOPERATIVE LEARNING}

There is a strong interest in today's Higher Education, especially in Engineering and Engineering Technology, in promoting cooperative learning among students. We can find several reasons that support this interest. The first, and probably the most important reason, is to eliminate the disparity between the way we teach our students and how engineers operate. Traditionally, most academic programs in engineering teach technical skills to the students although they do not stress the interpersonal and interprofessional skills that are required in the practice of any profession. Engineering technology professionals rely heavily on teamwork while engineering technology education does not include team work as much as would be desirable to prepare them. Education has traditionally been teacher-centered as the instructor gives information to the students hoping that they will remember and assimilate these new concepts, without encouraging the students to share this information between each other. This unilateral approach to education values the work of an individual but does not value his or her abilities to work within a group. Cooperative learning tries to solve this problem, moving education towards a learner-centered approach, stressing the importance of communication skills and teamwork. Another reason to introduce cooperative learning in our classrooms is based on the current research that shows that students learn more and better if they are involved in the delivery of the educational contents (Mourtos, 1997).

When cooperative learning is used in an Engineering or Engineering Technology program, it is traditionally done through a capstone design course, normally during the student's senior year, although in the most recent literature we can see how faculty is introducing concepts of cooperative learning in other courses (Catalano and Catalano, 1999). In this paper, the author will share his experiences incorporating cooperative learning in the Electrical Engineering Technology program at the Wilkes-Barre Campus of the Pennsylvania State University. The readers should be advised that these experiences are a work in progress as these new approaches are part of a continuous experimentation process aimed at improving the quality of our higher education.

\section{THE INTRANET TOOL: FIRST CLASS}

We have incorporated cooperative learning in an Electrical Engineering Technology program by modifying the contents and the delivery method in the capstone design courses in our program. This design content in this program is structured along two courses, the Project Proposal course (EET 419) and the Design Project (EET 420) that the students take sequentially in two semesters. This paper focuses on the approaches introduced in the Project Proposal course (EET 419) to increase the level of cooperative learning among the students. The outcome of this course is a technical document that analyzes and describes a project that the students will build in the next course.

The tool that has been chosen to incorporate cooperative learning in this course is an Intranet tool, based on First Class ${ }^{\mathrm{TM}}$ that is an asynchronous conferencing software. This software is available to all students in our academic labs as well as on their personal computers as the client allows it to be freely distributed. Each student has their own account on the system that allows 
them to access a number of folders. Some of these folders, such as Mail, News, etc are common to all the students while the rest of the folders have been created by the instructors of the different subjects that use First Class ${ }^{\mathrm{TM}}$. The folder that was created for this course works like a bulletin board that is accessible only by the students and instructor enrolled in that particular course, thus creating a virtual learning community. The instructor controls the level of permissions for the participants in that conference. These permissions give or deny the participants the possibility to edit other messages, delete their own or other's messages, etc.

Permission setting is dependent on how the students will work in that conference. For example, if several students are going to work together to produce a final document, it is desirable that they are allowed to edit and modify documents, while if this will not happen then it may be desirable to disable this possibility. A very convenient feature of this software is that for each message that has been posted on the board, the instructor knows when and who created the message, which students read the message and when, downloaded an attachment if there was any, replied to the message, etc., which is very helpful to manage the conference. The members of the conference can send messages to a single person or to the whole group. The response to a message can also be directed to a single individual or the whole conference. The software also has a real time chat capability that students can use to communicate with their friends and has also been used by instructors in other courses to hold remote office hours. This last feasibility is important for commuter campus such as ours, where sometimes students do not spend a lot of time on campus. This gives them the possibility to communicate with their peers when it is convenient for everybody.

\section{THE PROJECT PROPOSAL PREPARATION COURSE}

As it has been mentioned in the previous section, the work of a capstone design project has been divided into two courses, both taken by the students in their senior year. The outcome of the Proposal Preparation (EET 419) is a technical document that describes, analyzes and proposes a design solution to a problem that the students have chosen at the beginning of the course. The main goal of this course is to help students to become familiar with the different steps that need to be covered in a design process. By introducing cooperative learning in this course, we will also help them to become familiar with teamwork, constructive criticism, sharing responsibilities within the group, etc.

This course has been structured in a series of outcomes and task for the students to cover as is shown in the table below.

\section{INTRODUCTION}

- What is Project Proposal

- Expectations and goals of the course

- First Class Training

- $\quad$ Choose 3 or 4 topics suitable for the Senior Project

Outcome Task1: List and submit 3 to 4 topics of interest for the Senior Project. 


\section{DISCUSSION OF POSSIBLE TOPICS}

- Discussion of topics submitted by each group in the First Class environment

- Identify strengths and weaknesses of each proposed topic, difficulty, originality and viability to design and build it in the Spring Semester

- Engage in a positive dialogue with the authors of the topics

- Carry out search of resources available on the topic that has been selected

- The final decision on the topic is responsibility of the student. The instructor will suggest what topics are the most adequate

- Each student is required to provide feedback for at least 4 topics of discussion

- Remember that $10 \%$ of your grade is based on your interaction with other students in addition to the points for this task. This is a good place to earn those points!!

Outcome Task 2: Each group should select their topic based in group input

\section{BACKGROUND HISTORY SEARCH}

- Carry out research on the topic selected

- Find and reference work that describes similar and previous designs

- Study the evolution of the topic

- Provide a list of 5 or more hyperlinks that are of interest to the topic your group have selected

- Pointing out resources to other groups is another way to increase the $10 \%$ interaction points!

Outcome Task 3:Document with the results of the background search List of hyperlinks with information about your specific project

\section{DEFINITION OF YOUR PROJECT}

- Define your final project regarding modification and improvement from an existing design

- Define specifications of the design, based on intended applications, literature search and existing designs

- Define clearly how your design will improve existing designs

- Define clearly what part will be original and what part is based on existing material

Outcome Task 4: First Project Proposal with key references

\section{PLANNING THE PROJECT}

- Develop a timeline for the design

- Identify milestones in the design and building of the circuit

- List of tasks to be accomplished in a biweekly basis

- Reassessment viability of project in 15 weeks. Reanalysis and changing goals if necessary

Outcome Task 5: Time chart with proposed accomplishments

6 GLOBAL SYSTEM CONCEPT AND ANTICIPATION OF POSSIBLE PROBLEMS

- Break into categories:Analog, Digital, Interface, Software

- Anticipate possible technological problems that you expect may happen in EET 420

Outcome Task 6:Complete system block diagram

Block diagram for each category and interconnection including software if used Provide a list of possible problems in developing design 
- Provide full schematics for your project

- Run first simulations on PSPICE

- Determine critical components (those which are less commonly used)

Outcome Task 7: Submission of full schematics Submission of results from simulations

\section{LOCATE CRITICAL PARTS}

- Find at least 2 commercial devices for each critical component.

- Find manufacturers

- Contact manufacturer for samples or donations

Outcome Task 8: List of phone numbers, contact persons, etc. Copies of email, letters for donations, etc.

9 WRITE AND SUBMIT DEFINITE PROPOSAL

- Wrap up and finalize previous work

Outcome Task 9: Technical document for use in the Project Design (EET 420)

10 PROJECT PROPOSAL ORAL PRESENTATION

- Students present Project Proposal to the group

- Each group should answer questions from the Instructor and other groups

Outcome Task 10: Oral presentation of the Project Proposal

Once the students finish all of their tasks, they have a consistent proposal for the project that they want to build. By the way that the different outcomes are structured, we ensure that the different groups of students will communicate with each other and will share the information that they have found while doing research for their own project. In this way, they become used to working inside and outside their groups from the very beginning of the course. In the first weeks of class, the students become familiar with the Intranet tool and with the process of sharing ideas and information with the whole group. This helps to create the feeling of a learning community working together to achieve a common goal from the very first weeks of class.

We must be aware that there is normally some reluctance by the students to jump into this kind of work of sharing information with their peers and exposing their ideas to them to be criticized. The interaction that is required between students in the first outcomes is very non-judgmental as the students are only required to post their ideas and provide links to other groups if it is possible. It is also critical for the instructor to keep a very active role, not only monitoring the answers provided by the different groups, but also inciting group discussions by asking openended questions, pointing out some ideas, or referencing personal experiences with some approaches that some other groups want to pursue, etc. 


\section{CONCLUSIONS}

This paper has described the use of Intranet tools to teach a Project Proposal course that enhances cooperative learning. The benefits of cooperative learning are multiple, as it helps students to become more involved in the subject matter, to advance their learning through cooperation with their peers and to become familiar with teamwork. However, although the benefits of cooperative learning are obvious, it is not void of drawbacks. In first place, as students are not used to this kind of interaction in the classroom, experiences with cooperative learning should be slow and cautious, explaining to the them the reasons beyond each one of these activities. Secondly, these approaches put additional work on the faculty who need to carefully consider the balance between this additional work load and its possible benefits (Dutson, 1997).

In any case, any approach that is designed to address teamwork, interpersonal and interprofessional relationships within the field of study is critical for the success of our graduates as entry-level engineers (Katz, 1993). We certainly believe that this approach of using cooperative learning to this extent will synergistically enhance both the technical and interpersonal skills of our graduates, making them to become extremely qualified professionals at the service of the society.

\section{REFERENCES}

Catalano G. D. and Catalano K. (1999). Transformation: From teacher-centered to student-centered engineering education. Journal of Engineering Education, pp.59-64

Dutson, A J. et al (1997) A review of literature on teaching engineering design through Project-Oriented capstone courses. Journal of Engineering Education, pp. 17-28

Katz, S M (1993) The entry-level engineer: Problems in transition from student to professional. Journal of Engineering Education, pp. 171-174

Mourtos, N.J. (1997) The nuts and bolts of cooperative learning in engineering. Journal of Engineering Education, pp. $35-37$

ALBERT LOZANO-NIETO is Assistant Professor of Engineering at Penn State, Wilkes-Barre Campus. He teaches in the Biomedical Engineering Technology and Electrical Engineering Technology programs. His research interests are focused on Bioengineering, social implications of technology and developing cooperative learning in Engineering Technology 